\title{
The Relationship Between Birthweight Discordance and Perinatal Mortality of One of the Twins in a Twin Pair
}

\author{
Noriko Kato' and Tomohiro Matsuda ${ }^{2}$ \\ ' Department of Education Training Technology and Development, National Institute of Public Health, Saitama, Japan \\ ${ }^{2}$ Department of Epidemiology, National Institute of Public Health, Saitama, Japan
}

\begin{abstract}
$T^{\text {h }}$ his study aimed to evaluate the prevalence of birthweight discordance among twins, to determine the risk cut-off point for birthweight discordance, and to clarify whether perinatal deaths are aggravated by birthweight discordance or by low birthweight itself. A population-based analysis of all twins born between 1995 and 1999 in Japan was conducted using data collected from national birth, death and stillbirth certificates. Birthweight discordance was determined as: higher birthweight minus lower birthweight divided by higher birthweight multiplied by 100 . Among twins with a birthweight discordance of more than $15 \%$, the fetal and perinatal mortality rate was higher than that of twins with a discordance of less than $15 \%$. Ninety per cent of the relative cumulative frequency of twin live-births were within $25 \%$ of the birthweight discordance. Logistic regression analysis showed that the stillbirth of at least one of the twins is associated with the birthweight of the larger twin and birthweight discordance. It also showed that the stillbirth of both twins in the twin pair is associated with the birthweight of larger twins and the gestational weeks. It was clarified that birthweight discordance was associated with the stillbirth of only one twin in the twin pair, and the stillbirth of both twins in the twin pair was associated with low birthweight itself.
\end{abstract}

The birthweight discordance of fetuses is a common problem in twin pregnancies, occurring with a frequency that varies according to the definition used (Blickstein, 1991), with the cut-off points of birthweight difference to larger twins between $10 \%$ and $30 \%$. In addition to the fetal risk, smaller twins of birthweight discordant pairs are at increased risk of less favorable mental and physical development, which can consequently lead to disadvantages in adult life (Goyen et al., 2003). Birthweight discordances is caused by twin-to-twin transfusion, or abnormal functioning of the twins' placenta (Fraser et al., 1994). Intertwin birthweight disparity may result from a combination of intrinsic variations between the siblings and extrinsic factors that affect fetal growth (Blickstein et al., 1999). Thus, risk may arise either from low birthweight itself, or from the birth- weight discordance. However, the standard definition for a clinically significant growth difference of individuals within a twin pair has not been fully established, making it difficult to compare the risk of birthweight discordance among previous studies (Blickstein \& Kalish, 2003; Blickstein \& Keith, 2004; Branum \& Schoendorf, 2003).

The aim of this study is to determine the prevalence of birthweight discordance among twins born in Japan, to clarify how birthweight discordance affects perinatal mortality in association with other risk factors, and to examine the clinical and public health implications of intrapair birthweight discordance in a large population of twin births. We conducted the analysis with the hypothesis that birthweight discordance is associated with the stillbirth of only one twin within the twin pair; associated with low birthweight itself is the stillbirth of both twins within a twin pair. It is hoped that the study results will contribute to improved perinatal outcomes for twin pregnancies.

\section{Materials and Methods}

In Japan, birth, death and stillbirth certificates are collected by local administrative offices and collected by the Ministry of Health, Welfare and Labor who store the data files on magnetic tape. These data were used for this study, having been identified from certificates for births $(110,231$ cases $)$, stillbirths $(8365$ cases) and infant deaths (1036 cases) from 1995 to 1999. The data included information regarding sex, birthweight, gestational age (GA), parity, birth order, and the ages of the father and mother.

As the database does not link the certificates of twins, twins were firstly matched into pairs in order to determine whether the sex of the twins were analogous or disparate, and how large the birthweight discordance was. Criteria used for the identification of twins

Received 23 August, 2004; accepted 15 November, 2005.

Address for correspondence: Noriko Kato, Department of Education Training Technology and Development, National Institute of Public Health, 2-3-6 Minami, Wako-shi, Saitama, 351-0197 Japan. E-mail: kato@niph.go.jp 


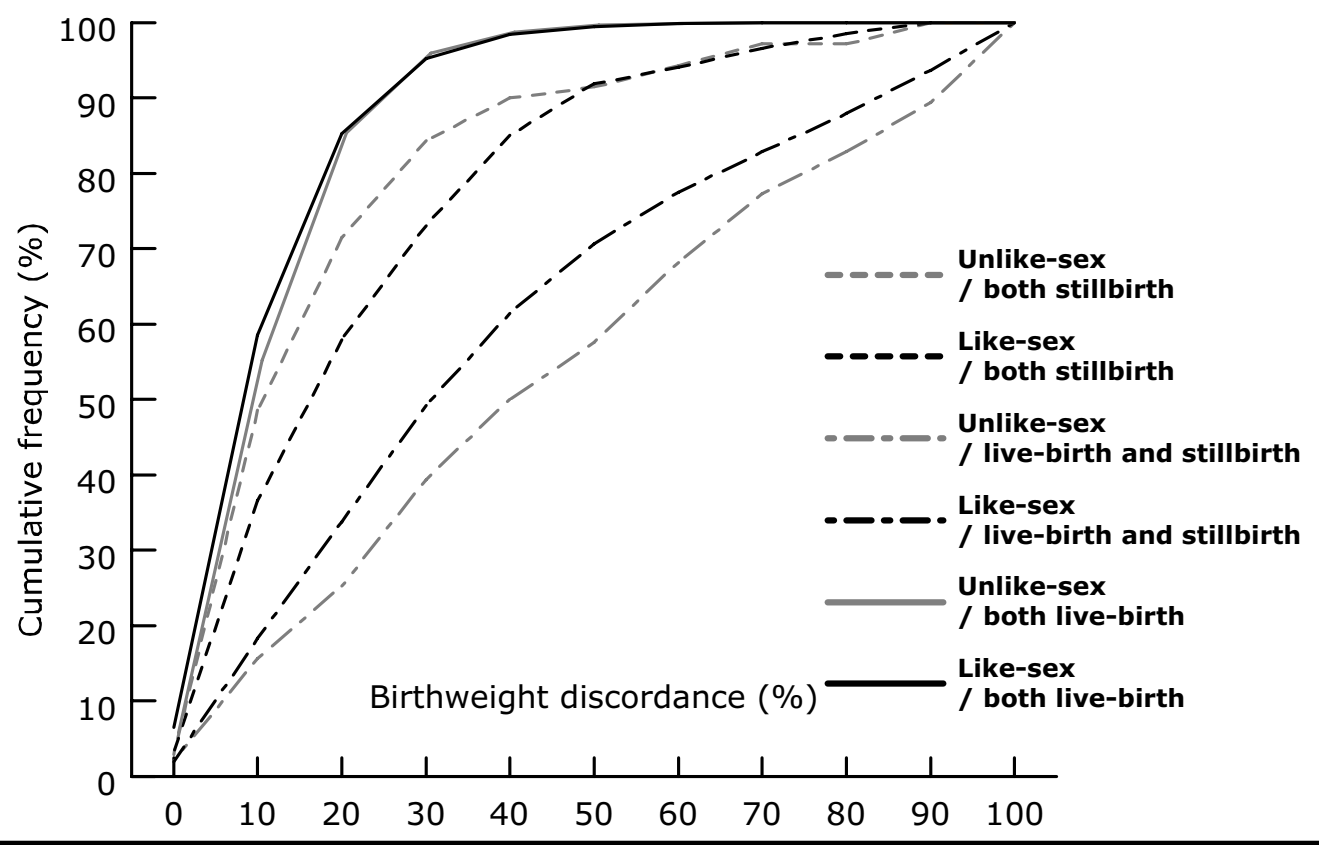

Figure 1

Cumulative frequency of twin birth according to sex and vital status of twins.

were: (1) the twin siblings were born in the same municipalities, (2) the second twin was born within 10 days of the first twin, and (3) the difference in ages of the parents were within 1 year. Of the twin birth certificate, $98.5 \%$ were paired using this method. Death certificates were linked to birth certificates using the same criteria. Using this method, $96.7 \%$ of death certificates could be linked to birth certificates. The percentage of unpaired birth or stillbirth certificates $(1.5 \%)$ and unlinked death certificates $(3.3 \%)$ indicates the exactness of the database. Twins with an unnatural combination of birthweight and GA, defined by standard gender and GA charts, with a recorded birthweight of more than 3 standard deviations from the mean, presumed to be due to the registration error, were eliminated. Following this method, 51,910 livebirth-live-birth twins, 957 live-birth-stillbirth twins, 466 stillbirth-live-birth twins, and 3166 stillbirth-stillbirth twins remained for analysis in this study. Birthweight discordance was calculated by dividing the difference in co-twin birthweights by the birthweight of the larger twin. Cumulative relative frequencies were calculated according to the outcome (live-born or stillbirth) combination and sex combination in order to clarify in what situation birthweight discordance is likely to appear.

The fetal death and perinatal mortality rates were calculated according to the formula that the Ministry has applied for annual statistics since 1995, which is the number of stillbirths after 22 weeks of gestation divided by the sum of the number of live-births and stillbirths after 22 weeks of gestation multiplied by 1000 . The perinatal mortality rate was calculated as the number of stillbirths after 22 weeks of gestation plus early neonatal deaths divided by the sum of the number of live-births and stillbirths after 22 weeks of gestation multiplied by 1000 .

Factors associated with at least one twin of a twin pair being stillborn and those associated with both twins of a twin pair being stillborn were investigated in order to clarify the association between the fetal death of only one twin of the twin pair and the birthweight discordance. Using logistic regression analysis, 53,248 pairs were analyzed. Of these, 1704 pairs had at least one stillborn twin, and 538 pairs had both twins stillborn. Logistic regression analysis was performed on significant factors, such as the age of the mother and the birth order of individual twin siblings and twins as a pair (presented in Tables 1 and 2), using the SPSS 11.5 statistical package for Windows, to adjust for confounding factors (SPSS Inc., 2001).

\section{Results}

The relative cumulative frequency of birthweight discordance with each sex combination and outcome combination category is shown in Figure 1. The proportion of twins with a birthweight discordance of less than $15 \%$ was least in the unlike-sex pairs with live and stillbirth combinations $(20.2 \%)$, followed by likesex pairs with live and stillbirth combinations $(25.8 \%)$, like-sex stillbirth twins $(46.6 \%)$, unlike-sex stillbirth twins $(60.0 \%)$, and like-sex live twins $(74.7 \%)$ and unlike-sex live twins $(73.1 \%)$. At $25 \%$ birthweight discordance, cumulative frequencies were calculated for unlike-sex live and stillbirth combinations $(31.3 \%)$, like-sex live and stillbirth combinations $(41.0 \%)$, like-sex stillbirth twins $(65.4 \%)$, unlike-sex 


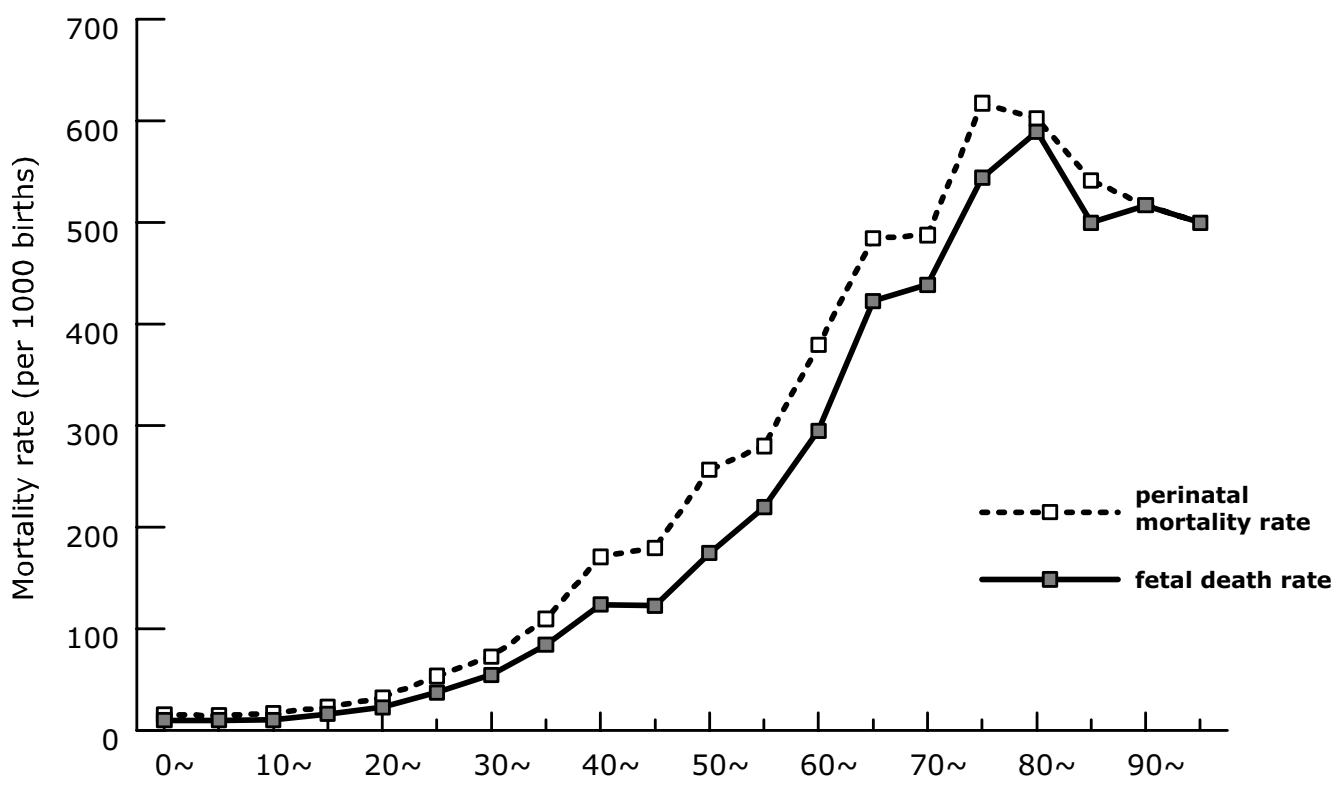

Birthweight discordance (\%)

Figure 2

Birthweight discordance and fetal/perinatal mortality.

stillbirth twins $(78.6 \%)$, like-sex live twins $(91.5 \%)$, and unlike-sex live twins $(92.3 \%)$. For live twins, the cumulative relative frequency was around $90 \%$ for twins with a $25 \%$ birthweight discordance for like-sex and unlike-sex twins.

The fetal death and perinatal mortality rates for each birthweight discordance category are shown in Figure 2. Fetal death rate and perinatal mortality rate were the lowest (10.1 and 14.8, respectively) in the 5\% to $10 \%$ birthweight discordance category, which were statistically similar to those in categories with the birthweight discordance of $0 \%$ to $5 \%$, and $10 \%$ to $15 \%$. Fetal and perinatal mortality rates increased when the birthweight discordance was greater than $15 \%$, when the risk tripled, and were more than five times the level of the 0 to $14 \%$ birthweight discordance category when the birthweight discordance was $30 \%$.

Effects of the factors affecting at last one twin being stillborn within the twin pair are shown in Table 1 . The crude odds ratio showed a strong effect of birthweight on larger twins, birthweight discordance and gestational weeks. After adjustment for confounding factors by logistic regression analysis, birthweight discordance was the major factor followed by the birthweight of the larger twin.

Table 2 shows the effects of the factors affecting the stillbirth of both twins within a twin pair. Univariate analysis showed the important effects of the birthweight of the larger twin and of gestational week. According to logistic regression analysis, the largest effect was the gestational week, followed by the birthweight of the larger twin within the twin pair.

\section{$\overline{\text { Discussion }}$}

Two factors affect the identification of the threshold of birthweight discordance: the relative cumulative frequency of birthweight discordance and the perinatal outcomes of birthweight discordance. While less than $10 \%$ of live-birth twins have a birthweight discordance larger than $25 \%$, the perinatal mortality becomes significantly higher when the birthweight discordance is greater than $15 \%$. Blickstein (1991) sent a questionnaire to 96 authors of twin-related obstetric articles in order to establish a protocol regarding the definition, diagnosis and management of growth-discordant twin gestations. Their results supported a two-grade definition, namely, mild (higher than 15\% and lower than $25 \%$ birthweight disparity) and severe (higher than 25\%) growth discordance. Our findings are consistent with Blickstein's (1991) definition of the birth discordance risk threshold.

The significance of birthweight discordance differs according to the severity of the discordance. Smaller twins in severely discordant pairs are at a disproportionate risk for perinatal mortality. Mild discordance is supposed to represent a normal variation between twin pairs, whereas severely discordant pairs often indicate the existence of some factor restricting normal growth. Mild discordance could also be seen as an adaptation to the limited intrauterine space in order to increase GA (Blickstein, 1991).

Our analyses estimated the risk of fetal death for twins both as individual twin siblings and as twins as a pair. Analysis was conducted on twins where one of the siblings was stillborn and on twins where both 
Table 1

Factors Associated With the Stillbirth of at Least One Twin of a Twin Pair

\begin{tabular}{|c|c|c|c|}
\hline \multirow[t]{2}{*}{ Risk factor } & \multirow[t]{2}{*}{ Categories } & \multicolumn{2}{|c|}{ Logistic regression analysis } \\
\hline & & $\begin{array}{c}\text { Crude odds ratio } \\
\text { (95\% confidence intervals) }\end{array}$ & $\begin{array}{c}\text { Odds ratio } \\
\text { (95\% confidence intervals) }\end{array}$ \\
\hline \multirow[t]{6}{*}{ Age of mother } & -19 & $1.3(0.8,2.2)$ & $0.9(0.5,1.6)$ \\
\hline & $20-24$ & $1.4(1.2,1.6)^{* *}$ & $1.2(1.0,1.5)^{*}$ \\
\hline & $25-29$ & $1.2(1.0,1.3)^{*}$ & $1.2(1.0,1.4)^{*}$ \\
\hline & $30-34$ & Reference & Reference \\
\hline & $35-39$ & $1.1(0.9,1.3)$ & $1.0(0.9,1.3)$ \\
\hline & $40-$ & $1.1(0.7,1.8)$ & $0.9(0.5,1.5)$ \\
\hline \multirow[t]{5}{*}{ Birthweight of larger twin $(\mathrm{kg})$} & $<1.0$ & $67.8(57.6,79.8)^{* * *}$ & $17.4(11.4,26.6)^{* * *}$ \\
\hline & $1.0 \leq<1.5$ & $15.8(13.2,18.8)^{* * *}$ & $3.4(2.4,4.8)^{* * *}$ \\
\hline & $1.5 \leq<2.0$ & $5.2(4.3,6.2)^{* * *}$ & $2.2(1.7,2.8)^{* *}$ \\
\hline & $2.0 \leq<2.5$ & $1.4(1.2,1.6)^{*}$ & $1.2(1.0,1.4)$ \\
\hline & $2.5 \leq$ & Reference & Reference \\
\hline \multirow[t]{4}{*}{ Gestational weeks } & $<28$ & $62.5(54.1,72.2)^{* * *}$ & $3.7(2.5,5.6)^{* * *}$ \\
\hline & $28 \leq<32$ & $14.8(12.7,17.3)^{* * *}$ & $2.1(1.5,2.8)^{* *}$ \\
\hline & $32 \leq<36$ & $3.2(2.8,3.7)^{* * *}$ & $1.5(1.2,1.8)^{* *}$ \\
\hline & $36 \leq$ & Reference & Reference \\
\hline \multirow[t]{2}{*}{ Sex combination } & Like-sexed & Reference & Reference \\
\hline & Unlike-sexed & $0.5(0.5,0.6)^{* *}$ & $0.6(0.5,0.7)^{* *}$ \\
\hline \multirow[t]{2}{*}{ Parity } & Primiparous & $0.8(0.8,0.9)^{* *}$ & $0.8(0.7,0.9)^{* *}$ \\
\hline & Multiparous & Reference & Reference \\
\hline \multirow[t]{2}{*}{ Previous stillbirth } & Absent & Reference & Reference \\
\hline & Present & $2.4(1.8,3.3)^{*}$ & $1.5(1.0,2.3)^{*}$ \\
\hline \multirow[t]{5}{*}{ Birthweight discordance (\%) } & $<15$ & Reference & Reference \\
\hline & $15 \leq<25$ & $2.0(1.7,2.3)^{* * *}$ & $2.0(1.7,2.4)^{* * *}$ \\
\hline & $25 \leq<35$ & $5.2(4.4,6.1)^{* * *}$ & $4.3(3.6,5.1)^{* * *}$ \\
\hline & $35 \leq<45$ & $12.6(10.5,15.2)^{* * *}$ & $7.9(6.3,9.8)^{* * *}$ \\
\hline & $45 \leq$ & $69.3(59.3,80.9)^{* * *}$ & $50.4(42.0,60.3)^{* * *}$ \\
\hline
\end{tabular}

Note: ${ }^{*} p<.05,{ }^{* *} p<.01,{ }^{* * *} \mathrm{p}<.001$.

were stillborn. To find out the effect on the perinatal mortality of twins, the actual birthweight, GA and birthweight discordance of the twins were adjusted for one another. Our analyses also controlled for the confounding effects of family status, and other important pregnancy-related factors, such as parity.

Increased perinatal death due to preterm gestation and low birthweight might have been observed in addition to birthweight discordance in the data used. However, our aim was to estimate the risk of perinatal death associated with birthweight discordance independent of the birthweight and GA of each twin as a pair and each twin as individual siblings.

The existing scientific evidence on the relationship between birthweight discordance and perinatal mortality is conflicting. Some studies (Cheung et al., 1995; Fraser et al., 1994; Rydhstrom, 1994; Talbot et al., 1997; Yalcin et al., 1998) report an association between birthweight discordance and fetal/infant death. In contrast to these findings, several studies challenge the clinical importance of birthweight discordance and argue that the actual birthweight of each twin within the pair, rather than the difference between the twins, is the most important determinant of outcome (Fraser et al., 1994; Talbot et al., 1997). In our study, the observation of individual siblings in twins was that birthweight was the strongest factor contributing to fetal death rates, and GA for early neonatal death. After adjusting for other factors, the effect of birthweight discordance was still significant both for fetal death and early neonatal mortality. In twins as a pair, the strongest factor affecting the fetal death of live and stillborn twins was the birthweight of the smaller co-twin, whereas the risk for live-birth twins was GA. After adjusting for other factors, the effect of birthweight discordance remained significant for live and stillborn twins, but for live-birth twins, little significance was found for birthweight discordance. 
Table 2

Factors Affecting the Stillbirth of Both Twins of a Twin Pair

\begin{tabular}{|c|c|c|c|}
\hline \multirow[t]{2}{*}{ Risk factor } & \multirow[t]{2}{*}{ Categories } & \multicolumn{2}{|c|}{ Logistic regression analysis } \\
\hline & & $\begin{array}{c}\text { Crude odds ratio } \\
(95 \% \text { confidence intervals })\end{array}$ & $\begin{array}{c}\text { Odds ratio } \\
\text { (95\% confidence intervals) }\end{array}$ \\
\hline \multirow[t]{6}{*}{ Age of mother } & -19 & $1.8(0.8,3.8)$ & $0.7(0.3,1.7)$ \\
\hline & $20-24$ & $1.8(1.4,2.4)^{* *}$ & $1.2(0.9,1.7)$ \\
\hline & $25-29$ & $1.2(0.9,1.4)$ & $1.1(0.8,1.4)$ \\
\hline & $30-34$ & Reference & Reference \\
\hline & $35-39$ & $0.8(0.6,1.2)$ & $0.8(0.6,1.2)$ \\
\hline & $40-$ & $1.4(0.7,3.0)$ & $1.0(0.4,2.3)$ \\
\hline \multirow[t]{5}{*}{ Birthweight of larger twin $(\mathrm{kg})$} & $<1.0$ & $398.6(266.4,596.5)^{* * *}$ & $16.8(6.7,42.0)^{* * *}$ \\
\hline & $1.0 \leq<1.5$ & $25.6(15.8,41.4)^{* * *}$ & $2.5(1.0,6.1)^{*}$ \\
\hline & $1.5 \leq<2.0$ & $5.7(3.3,9.7)^{* * *}$ & $1.5(0.7,3.2)$ \\
\hline & $2.0 \leq<2.5$ & $1.5(0.9,2.5)$ & $1.0(0.5,1.7)$ \\
\hline & $2.5 \leq$ & Reference & Reference \\
\hline \multirow[t]{4}{*}{ Gestational weeks } & $<28$ & $390.6(275.5,553.7)^{* * *}$ & $24.1(9.9,58.7)^{* * *}$ \\
\hline & $28 \leq<32$ & $25.7(16.8,39.3)^{* * *}$ & $7.4(3.2,16.9)^{* *}$ \\
\hline & $32 \leq<36$ & $4.1(2.6,6.4)^{* * *}$ & $3.1(1.7,5.5)^{*}$ \\
\hline & $36 \leq$ & Reference & Reference \\
\hline \multirow[t]{2}{*}{ Sex combination } & Like-sexed & Reference & Reference \\
\hline & Unlike-sexed & $0.4(0.3,0.5)^{* * *}$ & $0.5(0.4,0.7)^{* *}$ \\
\hline \multirow[t]{2}{*}{ Parity } & Primiparous & $1.0(0.8,1.2)$ & $1.0(0.8,1.2)$ \\
\hline & Multiparous & Reference & Reference \\
\hline \multirow[t]{2}{*}{ Previous stillbirth } & Absent & Reference & Reference \\
\hline & Present & $5.2(3.5,7.6)^{* * *}$ & $2.8(1.7,4.7)^{*}$ \\
\hline \multirow[t]{5}{*}{ Birthweight discordance (\%) } & $<15$ & Reference & Reference \\
\hline & $15 \leq<25$ & $1.6(1.3,2.1)^{* *}$ & $1.5(1.2,2.0)^{*}$ \\
\hline & $25 \leq<35$ & $(2.2,3.9)^{* * *}$ & $1.5(1.1,2.1)^{*}$ \\
\hline & $35 \leq<45$ & $(5.5,10.1)^{* * *}$ & $2.3(1.6,3.2)^{* *}$ \\
\hline & $\leq 45$ & $(6.9,12.6)^{* * *}$ & $2.1(1.4,2.9)^{* *}$ \\
\hline
\end{tabular}

Note: ${ }^{*} p<.05,{ }^{* *} p<.01,{ }^{* * *} p<.001$.

Blickstein and Keith (2004) have pointed out that severely discordant twins where the smaller co-twin is also small for GA are at an increased risk of neonatal death. Identification of this group is an imperative step in the management of birthweight discordance in twin gestations. Demissie et al. (2002) demonstrated that the increased risk of neonatal death among discordant twins is probably due to death from congenital anomalies. These results suggest that the association between stillbirth and weight difference may arise from a common origin. The risk increase was even higher for those small-for-gestational-age twins who were at the same time birthweight discordant.

The effect of birthweight discordance upon perinatal mortality should be interpreted in the light of potential differences between the fetal weight at death and birthweight as a result of fetal maceration (Demissie et al., 2002). In a study that estimated fetal weight 2 weeks before delivery and compared it with the actual birthweight (Nzeh et al., 1992), a significant difference was not found between the mean fetal weight and birthweight. However, if the interval between the death of one twin and the delivery of the co-twin is long, the birthweight of the dead twin may be unreliable. A well-designed study of twin pregnancy with a single stillborn fetus showed that $69 \%$ of mothers went into spontaneous labor within 7 days of diagnosis of a stillborn fetus, $86 \%$ within 35 days, and $100 \%$ within 56 days (Santema et al., 1995).

Research documents that there may be other risk factors affecting birthweight discordance. Yalcin et al. (1998) showed that the effect of birthweight discordance may differ according to GA. Several investigators have restricted their analyses of discordance to either preterm or term gestations (Cheung et al., 1995; Talbot et al., 1997). Demissie et al. (2002) performed analyses after stratifying the data by GA categories (17-31, 32-36 and 37-41 weeks). They 
adjusted several important confounding factors, including the actual birthweight of each twin (Demissie et al., 2002). An increase in birthweight discordance was associated with an increased risk of a stillborn fetus in the smaller and larger twin of the same sex, as well as in the smaller twin of oppositesex twins. Cheung et al. (1995) state that birthweight discordance does not differ according to chorionicity. Chorionicity is actually an important factor for the birth discordance of twins and fetal mortality (Demissie et al., 2002). Likewise, birth length is said to be a risk factor for perinatal mortality (Melve et al., 2000). Unfortunately, our study was not able to analyze the relationships between GA, sex combination, chorionicity and birth length. Thus, this limitation may introduce some bias into the analysis (David, 1980). Inaccuracy and incompleteness of GA based on the last menstrual period date as reported on the birth certificate can be another problem on data quality. This measure is subject to error, but has been demonstrated to be the most accurate available on a population-wide basis (Alexander et al., 1995). Similarly, the underreporting of stillborn fetuses is likely to occur on birth certificates and in stillborn fetus data in general (David, 1980).

In conclusion, these results provide evidence that increased twin birthweight discordance is associated with the increased intrauterine death of only one twin within the twin pair. Our study identified the clinically important threshold for birthweight discordance of twins, and we hope that this will lead to more accurate risk identification and thus, improved treatment in the clinical setting.

\section{Acknowledgments}

We thank the staff of the Department of Statistics and Information, Ministry of Health, Labor and Welfare of Japan for providing copies of the magnetic tape data on birth and death certificates. We also thank Ms T. Tanaka and Ms I. Morita for their technical assistance. This research was supported by a Grant-in-Aid for Scientific Research (KAKENHI, Grant No 13670407) from The Ministry of Education, Culture, Sports, Science and Technology (MEXT) of Japan.

\section{References}

Alexander, G. R., Tompkins, M. E., Petersen, D. J., Hulsey, T. C., \& Mor, J. (1995). Discordance between LMPbased and clinically estimated gestational age: Implications for research, programs, and policy. Public Health Reports, 110, 395-402.

Blickstein, I. (1991). The definition, diagnosis, and management of growth-discordant twins: An international census survey. Acta Geneticae Medicae et Gemellologiae, 40, 345-351.

Blickstein, I., Goldman, R. D., Smith-Levitin, M., Greenberg, M., Sherman, D., \& Rydhstroem, H. (1999). The relation between inter-twin birthweight discordance and total twin birthweight. Obstetrics and Gynecology, 93, 113-116.

Blickstein, I., \& Kalish, R. B. (2003). Birthweight discordance in multiple pregnancy. Twin Research, 6, 526-531.

Blickstein, I., \& Keith, L. G. (2004). Neonatal mortality rates among growth-discordant twins, classified according to the birthweight of the smaller twin. American Journal of Obstetrics and Gynecology, 190, 170-174.

Branum, A. M., \& Schoendorf, K. C. (2003). The effect of birthweight discordance on twin neonatal mortality. Obstetrics and Gynecology, 101, 570-574.

Cheung, V. Y., Bocking, A. D., \& Dasilva, O. P. (1995). Preterm discordant twins: What birthweight difference is significant? American Journal of Obstetrics and Gynecology, 172, 955-959.

David, R. J. (1980). The quality and completeness of birthweight and gestational age data in computerized birth files. American Journal of Public Health, 70, 964-973.

Demissie, K., Ananth, C. V., Martin, J., Hanley, M. L., MacDorman, M. F., \& Rhoads, G. G. (2002). Fetal and neonatal mortality among twin gestations in the United States: The role of intrapair birthweight discordance. Obstetrics and Gynecology, 100, 474-480.

Fraser, D., Picard, R., Picard, E., \& Leiberman, J. R. (1994). Birthweight discordance, intrauterine growth retardation and perinatal outcomes in twins. The Journal of Reproductive Medicine, 39, 504-508.

Goyen, T. A., Veddovi, M., \& Lui, K. (2003). Developmental outcome of discordant premature twins at 3 years. Early Human Development, 73, 27-37.

Melve, K. K., Gjessing, H. K., Skjaerven, R., \& Oyen, N. (2000). Infants' length at birth: An independent effect on perinatal mortality. Acta Obstetricia et Gynecologica Scandinavica, 79, 459-464.

Nzeh, D. A., Rimmer, S., Moore, W. M., \& Hunt, L. (1992). Prediction of birthweight by fetal ultrasound biometry. The British Journal of Radiology, 65, 987-989.

Rydhstrom, H. (1994). Discordant birthweight and late fetal death in like-sexed and unlike-sexed twin pairs: A population-based study. British Journal of Obstetrics and Gynaecology, 101, 765-769.

Santema, J. G., Swaak, A. M., \& Wallenburg, H. C. (1995). Expectant management of twin pregnancy with single fetal death. British Journal of Obstetrics and Gynaecology, 102, 26-30.

SPSS Inc. (2001). SPSS 11.5 base system, advanced models. [Computer software]. Chicago, IL: SPSS, Inc.

Talbot, G. T., Goldstein, R. F., Nesbitt, T., Johnson, J. L., \& Kay, H. H. (1997). Is size discordancy an indication for delivery of preterm twins? American Journal of Obstetrics and Gynecology, 177, 1050-1054.

Yalcin, H. R., Zorlu, C. G., Lembet, A., Ozden, S., \& Gokmen, O. (1998). The significance of birthweight difference in discordant twins: A level to standardize? Acta Obstetricia et Gynecologica Scandinavica, 77, 28-31. 